\title{
Nutritional reflection on growth and development among intellectually disabled children
}

\author{
Marwa Nasr Al Sayed ${ }^{1 *}$ (D) Mohamed Salah Mostafa ${ }^{2}$, Howida Hosny El Gebaly ${ }^{3}$, Rania Samy Mohamed ${ }^{3}$ \\ and Magda Ramzy Kastandy ${ }^{4}$
}

\begin{abstract}
Background: Many studies revealed that there is a strong relationship between neurodevelopmental delay and malnutrition. This clinic-based study aimed to detect nutritional problems and its reflection on growth and mental development through determination of the nutritional profile among disabled children.

Results: This study showed significant difference in the residential places between the two groups of lower and higher IQ. The birth order is significantly related to level of IQ in children. By applying food analysis, there is significant difference in the elements they get between the two groups of children (of lower and higher IQ). Multiple analysis showed significant relationship between orientation and zinc intake with IQ of children.

Conclusion: Intellectual disability is more prevalent in rural and popular residential. As the birth order increases, the percentage of lower IQ increases. Dietary profile for intellectually disabled children (of lower IQ) is regarded to be richer with dietary elements and vitamins than that for higher IQ children. According to the multiple analysis, orientation and zinc intake are the most effective variables on the $\mathrm{IQ}$ scores.
\end{abstract}

Keywords: Intellectual disability, Nutritional factors, IQ level, Socioeconomic impacts

\section{Background}

Low socioeconomic level was highly related to some sorts of disabilities such as mental retardation, delayed language, and behavior disorder; on the other side, some studies revealed that there is significant association between cerebral palsy and severe preterm maternal hypertension, antepartum hemorrhage, and preterm uterine activity (Taylor et al 1985).

Many studies have revealed that there is negative relationship between birth order and intelligence level. The explanation for this association is not well known; there are many suggested explanations: Such as that the relation is due to more-preferable family interaction and

\footnotetext{
*Correspondence: marwanasr73@hotmail.com

${ }^{1}$ Institute of Environmental Studies and Research, Ain Shams University,

El-Abaseya, Egypt

Full list of author information is available at the end of the article
}

stimulation of low-birth-order children, whereas others claim that the effect is caused by prenatal gestational factors. Child education is significantly affected by their family size (Tambi and Ewane 2019).

Many studies were applied in order to assess the association between gross motor development and IQ level for children. The relationship between gross motor development and cognition is not strong enough to allow the use of one to predict the other (Houwen et al. 2016).

Anemia is one of the probable health problems that appear in intellectually disabled children due to malnutrition; according to the previous study, it reaches $11.6 \%$ (Lin et al. 2010). The health impacts of anemia are usually noticed during infancy and early childhood as they are periods of significant growth and development of the central nervous system (Lozoff et al. 2006).

The human brain passes through consecutive changes in structure and functional connectivity throughout 
childhood and adolescence (Luna 2009). Diets consumed by children play an important role in the neurodevelopmental process (Krebs-Smith et al. 2010).

Although there were a lot of studies and intervention applied, anemia regarded to be one of the main nutritional deficiency disorders in the world today, as it is most prevalent in pregnant women and young children. Previous studies have shown that anemia is prevalent among children at age of 5 or less in Southern Asia and Africa, which are regarded to be developing countries. In developing countries, about $30-80 \%$ of preschool children were anemic (Mason et al. 2005) according to a study applied on Chinese preschool children in order to detect the relationship between anemia and the development of these children. It revealed that children who were exposed to developmental delays at infancy exhibited behavioral anomalies (Chang et al. 2011).

Anemia is defined as the condition of less than the normal quantity of blood hemoglobin $(\mathrm{Hb})$ which has physiological and psychological impacts on health. Anemia has serious consequences as it causes decreases in oxygen level in the body, including tissues and major organs, such as the brain. As a result, there are many symptoms associated with anemia, including physiological symptoms, such as cerebrovascular infarction (stroke), and psychosocial symptoms, such as decreased cognitive abilities and adverse behavioral outcomes, because of impairments in normal brain functions (Ai et al. 2012).

Fat is one of the main constituents in infants and young children diet, as they need an extraordinary energy to compensate their limited dietary capacity, moreover, essential fatty acids such as arachidonic acid, docosahexaenoic acid, and their metabolites, which plays an important role in children growth and development and its deficiency may affect maturation of the central nervous system, visual development, and intelligence (Hardya and Kleinman 2007).

\section{Aim of the study}

This study include nutritional assessment for disabled children which is important and benefitial for them.

\section{Methods}

\section{Subjects}

The study group of special need children age (3-6) years was recruited from the general pediatric clinic referred to center of children with special needs, Faculty of Post Graduate Childhood Studies, at Shams University.

A cross-sectional study was carried out for 100 children (65 male and 35 female) aged 3 years. Data on age, sex, weight, height, and severity of intellectual disability or global developmental delay were collected from medical records. Body mass index (BMI, weight/height ${ }^{2}$ ) was calculated and overweight and obesity defined using standard international criteria.

\section{Inclusion criteria}

All children with special needs aged from 3 to 6 years.

\section{Exclusion criteria}

- Children with chronic diseases (such as bronchial asthma that induces growth, chronic renal failure, hepatic disease, epilepsy that causes brain deterioration.

- Children treated with stimulant medication (Ritalin).

- Children treated with non-stimulant medication (Atomoxetine).

- Children with physical disabilities.

- Children with pica

\section{Method}

\section{Study design}

It is cross-sectional, observational clinic-based study.

\section{Phases of the study}

Study was conducted on children with special needs aged from 3 to 6 years attending to pediatric clinic at center of children with special needs-Faculty of Post Graduate Childhood Studies-Ain Shams University to receive medical treatment and follow-up services the study conducted from January 2018 to March 2020. One hundred children were collected (65 male and 35 female); their parents accompanying the child were informed about the aim of the study and the procedures.

Those children fulfilled the above mentioned criteria were subjected to:

- History taking includes: age, sex, onset, and duration of disorder and family history.

- Assessment of nutritional status using developmental nutritional questionnaire includes: Demographic and socioeconomic data including age, gender. WHO anthropometric measurement protocol was used; BMI was calculated as the weight in $\mathrm{kg}$ divided by the height square in meters (WHO 2005-2007).

Sheet of 24-h dietary recalls will be collected using the Multiple Pass Food Recall (MPR) method which is a 5-step approach, developed by the United State Department of Agriculture (USDA) (Moshfegh et al. 2008). 24-h recalls sheet was collected for each participant.

ESHA Research Food Processor SQL and ESHA Port SQL software version 10.3 were used to enter age, gender, and anthropometric information as well as every food 
item (portion, time, and meal). Food recipes and preparation information were collected for homemade food, and amount consumed by each subject was estimated. Nutrient analysis was obtained.

- Assessment of anthropometric measures (weight and height),

- Clinical examination

Full clinical examination was done including general examination and local examination in order to diagnose any chronic diseases (chest-abdomen-CNS-CVS) and exclude any other diseases then develop mental examination. The diagnosis was confirmed by the laboratory and radiological findings of the patients.

- Complete blood count with differential leucocytic count

- EEG was done by some patients to exclude epilepsy.

- IQ test: using Stanford-bennet 5th edition was carried out.

\section{Statistical method}

- Collected data entered and analyzed data were expressed as means \pm standard deviation or frequencies (\%), using PC computer and presented using appropriate statistical tests by SPSS statistical data program.

- Proper significant test was used according to type of data (Mostafa and El-Shourbagy 2010). After 12 months, 102 patients were recruited; the data could not be completed for 2 patients so the actual number of patients included in the study was 100 patients

Statistical analysis was done by statistical package for social sciences (spss) version 21. Qualitative variables are presented as number and percent and quantitative variables as mean and standard deviation. The proportions were compared using $\times 2$ test. In quantitative variables, comparison between two groups was done by $t$ test. $\mathrm{P}$ value less than 0.05 is significant level and less than 0.001 is highly significant level.

\section{Limitation}

- Loss of some cases as they were not cooperative complete their assessments

- We could not validate the data taken from the mothers

- We relied on the data reported by subjects
Table 1 The relation between IQ and the resident places

\begin{tabular}{lllll}
\hline Resident /IQ & $\begin{array}{l}\text { Intellectually } \\
\text { disabled }\end{array}$ & $\begin{array}{l}\text { Developmentally } \\
\text { delayed }\end{array}$ & $\mathbf{X}^{\mathbf{2}}$ & $\boldsymbol{p}$ \\
\hline Rural: no & 6 & 6 & 6.331 & 0.042 \\
$\%$ & $14.0 \%$ & $10.5 \%$ & & \\
Popular: no & 32 & 32 & \\
$\%$ & $74.4 \%$ & $56.1 \%$ & \\
Non-popular: no & 5 & 19 & \\
$\%$ & $11.6 \%$ & $33.3 \%$ & \\
Total: no & 43 & 57 & \\
$\%$ & $100 \%$ & $100 \%$ & \\
\hline
\end{tabular}

Table 2 The relation between IQ and birth order

\begin{tabular}{lllll}
\hline Birth order & IQ test $\leq \mathbf{7 5}$ & IQ test $>\mathbf{7 5}$ & $\mathbf{X}^{\mathbf{2}}$ & $\boldsymbol{p}$ \\
\hline$\leq 2$ & & & & \\
No & 24 & 40 & 3.280 & 0.070 \\
$\%$ & $55.8 \%$ & $70.17 \%$ & & \\
$>2$ & & & \\
No & 19 & 17 & \\
$\%$ & $44.2 \%$ & $29.83 \%$ & \\
Total & & & \\
No & 43 & 57 & \\
$\%$ & $100 \%$ & $100 \%$ & \\
\hline
\end{tabular}

\section{Results}

Table 1 shows the distribution of children according to their residential places as follows: rural area of $14 \%$, popular area of $74.4 \%$, and non-popular area of $11.6 \%$, on the other hand the distribution for the second group as follows: rural area of $10.5 \%$, popular area of $56.1 \%$ and nonpopular area33.3\% $p=0.042$ that less than 0.05 indicates significant difference between the two groups in the place of residence.

Table 2 shows that in the first group $55.8 \%$ of them their birth order were the first or second, versus $70.17 \%$ of the second group, the difference between the two groups is near to be significant as $\mathrm{p}=0.070$.

The prevalence of gross motor delayed cases among the intellectually disabled children (group of lower IQ) is $29.9 \%$ on the other hand this percentage decreases to $5.3 \%$ in case of higher IQ children (there IQ $>75$ ) There is significant variation between the two groups in the gross motor development as $p=0.002$ (Table 3).

Table 4 shows that in the first group 14\% considered to be hyperactive versus $29.8 \%$ of the second group. The difference between the two groups is close to be significant as $p=0.062$.

Table 5 shows that the total leukocytic count for the group of intellectually disabled children mean value is 
Table 3 The relation between IQ and gross motor development

\begin{tabular}{lllll}
\hline Gross motor & IQ test $\leq \mathbf{7 5}$ & IQ test $>\mathbf{7 5}$ & $\mathbf{X}^{\mathbf{2}}$ & $\boldsymbol{p}$ \\
\hline Normal & & & & \\
No & 31 & 54 & 9.857 & .002 \\
$\%$ & $72.1 \%$ & $94.7 \%$ & & \\
Delayed & & & \\
No & 12 & 3 & \\
$\%$ & $27.9 \%$ & $5.3 \%$ & \\
Total & & & \\
No & 43 & 57 & \\
$\%$ & $100.0 \%$ & $100.0 \%$ & \\
\hline
\end{tabular}

Table 4 The relation between hyperactivity and IQ

\begin{tabular}{|c|c|c|c|c|}
\hline Hyperactivity & IQ test $\leq 75$ & IQ test $>75$ & $x^{2}$ & $p$ \\
\hline \multicolumn{5}{|l|}{ Normal } \\
\hline No & 37 & 40 & 3.486 & .062 \\
\hline$\%$ & $86.0 \%$ & $70.2 \%$ & & \\
\hline \multicolumn{5}{|l|}{ Hyperactive } \\
\hline No & 6 & 17 & & \\
\hline$\%$ & $14.0 \%$ & $29.8 \%$ & & \\
\hline \multicolumn{5}{|l|}{ Total } \\
\hline No & 43 & 57 & & \\
\hline$\%$ & $100.0 \%$ & $100.0 \%$ & & \\
\hline
\end{tabular}

Table 5 Distribution of laboratory data according to IQ test

\begin{tabular}{lccccc}
\hline Variable & IQ test $\leq \mathbf{7 5}$ & IQ test $\mathbf{7 5}$ & Total & $\mathbf{X}^{\mathbf{2}}$ & $\boldsymbol{p}$ \\
\hline $\mathrm{Hb}$ & & & & & \\
No & 11.3 & 11.0 & 11.1 & 1.423 & 0.158 \\
$\%$ & $1.3 \%$ & $1.4 \%$ & $1.3 \%$ & & \\
$\mathrm{TLC}$ & & & & & \\
No & 7.6 & 6.2 & 6.8 & 2.560 & 0.012 \\
$\%$ & $2.9 \%$ & $2.3 \%$ & $2.7 \%$ & & \\
Platelets & & & & & \\
No & 275.3 & 261.3 & 267.6 & 1.166 & 0.246 \\
$\%$ & $64.2 \%$ & $55.9 \%$ & $59.9 \%$ & & \\
\hline
\end{tabular}

* Data presented by mean (SD)

7.6 decreases to 6.2 for the group of higher IQ level, the calculated $p=0.012$ which less than 0.05 and approximately equal 0.01 so there is highly significant difference between the two groups.

Table 6 shows higher Calories intake for the intellectually disabled (lower IQ children) with calculated $p=0.008$ which less than 0.01 so there is high significant difference between the two groups. Also, carbohydrate intake regarded to be higher for the lower IQ group with calculated $p=0.028$ which less than 0.05 , so there is significant difference between the two groups. The intellectually disabled children (group of lower IQ) has higher protein intake, the calculated $p=0.029$ which less than 0.05 so there is significant difference between the two groups. Also, Fat intake for the lower IQ group is higher than the group of higher IQ with calculated $p=0.012$ which is regarded to be significant difference between the two groups. Higher fiber intake is recorded for the lower IQ group of children the $p=0.022$ which is less than 0.05 so there is significant difference between the two groups.

Sodium intake and potassium intake are also recorded higher for the lower IQ group with calculated $p=0.041$ and $p=0.002$ which shows significant and highly significant difference between the two groups. Calcium and Iron intake are also higher for the low IQ group of children but the difference between the two groups is close to be significant. Zinc intake is higher for the group of intellectually disabled children $p=0.039$ which less than 0.05 so there is significant difference between the two groups.

The following independent variables (age, diagnosis, gross motor, height, birth order, orientation, hyperactivity, TLC, education, BMI, water, $\mathrm{CHO}$, protein, fat, $\mathrm{Na}$, $\mathrm{K}, \mathrm{Ca}, \mathrm{Mg}$, and $\mathrm{Zn}$ ) affect $75 \%$ on the IQ score $p=0.001$, multiple $r=0.745$.

Orientation is significantly related to the IQ of children by $48.7 \%$ and zinc intake affect IQ by $33.3 \%$, in the presence of the other factors (Table 7).

\section{Discussion}

In the present study, the distribution of children in the first group according to their residential places is as follows: rural area of $14 \%$, popular area of $74.4 \%$, and nonpopular area of $11.6 \%$. Rural areas and popular areas had higher ID prevalence rate than urban areas, which matches with study by Lai et al. (2011), which revealed that rural areas had higher incidence than urban areas. On the other hand, it goes against the study applied on Indian children by Lakhan et al. (2015) showing that the intellectual disability prevalence rate in children is slightly higher in urban than rural areas. So it needs further study.

In the present study, the distribution of the group of lower IQ is higher percentage of birth order more than 2; according to the results of the previous study, IQ scores were negatively associated with both birth order and social order (Kristensen and Bjerkedal 2007).

In the present study, there is significant relationship between IQ and gross motor development, which goes with a study by Rintala and Loovis (2013) that showed 
Table 6 (Mean \pm SD) of food analysis data according to IQ test

\begin{tabular}{|c|c|c|c|c|c|}
\hline Variable & $\begin{array}{l}\text { IQ test } \leq 75 \\
\text { Mean } \pm S D\end{array}$ & $\begin{array}{l}\text { IQ test }>75 \\
\text { Mean } \pm \text { SD }\end{array}$ & $\begin{array}{l}\text { Total } \\
\text { Mean } \pm \text { SD }\end{array}$ & $t$ & $p$ \\
\hline Calories & $1375.4 \pm 547.3$ & $1089.3 \pm 410.7$ & $1218.0 \pm 495.6$ & -2.650 & 0.008 \\
\hline Carbohydrate & $177.1 \pm 77.4$ & $143.9 \pm 61.1$ & $158.8 \pm 70.5$ & -2.193 & 0.028 \\
\hline Protein & $44.8 \pm 22.3$ & $35.3 \pm 16.0$ & $39.6 \pm 19.6$ & -2.186 & 0.029 \\
\hline Fat & $54.1 \pm 28.5$ & $41.4 \pm 21.8$ & $47.1 \pm 25.7$ & -2.512 & 0.012 \\
\hline Fiber & $3.9 \pm 1.8$ & $3.1 \pm 1.9$ & $3.5 \pm 1.9$ & -2.287 & 0.022 \\
\hline Sodium & $1775.8 \pm 1142.0$ & $1365.6 \pm 705.9$ & $1550.2 \pm 945.2$ & -2.047 & 0.041 \\
\hline Potassium & $1566.6 \pm 744.6$ & $1113.6 \pm 610.0$ & $1317.5 \pm 707.6$ & -3.101 & 0.002 \\
\hline Calcium & $476.4 \pm 45$ & $357.3 \pm 282.9$ & $410.9 \pm 375.8$ & -1.784 & 0.074 \\
\hline Phosphorus & $534.0 \pm 300.8$ & $467.2 \pm 253.3$ & $497.3 \pm 276.3$ & -1.646 & 0.100 \\
\hline Magnesium & $78.2 \pm 61.7$ & $59.5 \pm 38.9$ & $68.1 \pm 51.2$ & -1.736 & 0.083 \\
\hline Iron & $7.0 \pm 3.3$ & $5.8 \pm 2.9$ & $6.3 \pm 3.1$ & -1.777 & 0.076 \\
\hline Zinc & $5.3 \pm 2.4$ & $4.4 \pm 2.3$ & $4.8 \pm 2.4$ & -2.065 & 0.039 \\
\hline Cupper & $0.5 \pm 0.4$ & $0.5 \pm 0.4$ & $0.5 \pm 0.4$ & -0.792 & 0.429 \\
\hline Vitamin A & $681.2 \pm 2227.7$ & $665.7 \pm 2614.7$ & $672.9 \pm 2428.3$ & -0.902 & 0.367 \\
\hline Vitamin C & $41.0 \pm 80.2$ & $29.1 \pm 40.3$ & $0.9 \pm 1.1$ & -0.046 & 0.963 \\
\hline Vitamin B1 & $0.4 \pm 0.3$ & $0.4 \pm 0.3$ & $0.6 \pm 0.8$ & -0.064 & 0.949 \\
\hline Vitamin B2 & $0.9 \pm 1.1$ & $0.6 \pm 0.8$ & $0.7 \pm 1.0$ & -2.098 & 0.036 \\
\hline
\end{tabular}

Table 7 Multiple analysis of the independent variables (age, diagnosis, gross motor, height, birth order, orientation, hyperactivity, TLC, education, BMI, water, $\mathrm{CHO}$, protein, fat, $\mathrm{Na}, \mathrm{K}, \mathrm{Ca}, \mathrm{Mg}$, and $\mathrm{Zn}$ ) on IQ score

\begin{tabular}{|c|c|c|c|c|c|}
\hline Model & $B$ & SD & Beta & $t$ & Sig \\
\hline Constant & 67.441 & 24.676 & & 2.733 & 0.008 \\
\hline Age & -0.119 & 0.231 & -0.088 & -0.516 & 0.607 \\
\hline Diagnosis & -0.117 & 0.921 & -0.012 & -0.127 & 0.899 \\
\hline Gross Motor & -4.44 & 5.593 & -0.086 & -0.794 & 0.43 \\
\hline Height & 0.357 & 0.302 & 0.196 & 1.183 & 0.241 \\
\hline Birth Order & 1.655 & 1.363 & 0.111 & 1.215 & 0.229 \\
\hline Orientation & -20.358 & 4.319 & 0.487 & 4.714 & 0 \\
\hline Hyperactivity & -2.356 & 3.866 & 0.055 & 0.609 & 0.544 \\
\hline $\mathrm{TLC}$ & -0.516 & 0.63 & -0.077 & 0.819 & 0.415 \\
\hline Education & 4.066 & 3.045 & 0.137 & 1.335 & 0.186 \\
\hline $\mathrm{BMI}$ & 0.152 & 0.81 & 0.018 & 0.187 & 0.852 \\
\hline Water & -0.019 & 0.017 & -0.254 & 1.134 & 0.26 \\
\hline $\mathrm{CHO}$ & 0.015 & 0.033 & 0.056 & 0.442 & 0.66 \\
\hline Protein & -0.217 & 0.193 & -0.232 & 1.125 & 0.264 \\
\hline Fat & -0.054 & 0.107 & -0.078 & -0.508 & 0.613 \\
\hline $\mathrm{Na}$ & -0.002 & 0.003 & -0.127 & -0.929 & 0.356 \\
\hline K & -0.001 & 0.005 & -0.031 & -0.165 & 0.869 \\
\hline $\mathrm{Ca}$ & 0.003 & 0.01 & 0.066 & 0.324 & 0.747 \\
\hline $\mathrm{Mg}$ & 0.001 & 0.071 & 0.002 & 0.012 & 0.99 \\
\hline $\mathrm{Zn}$ & 2.838 & 1.343 & 0.333 & 2.113 & 0.038 \\
\hline
\end{tabular}

that intellectually disabled children have low gross motor skills on the other hand it is against the previous study revealed that there is no significant association between cognition aspects and gross motor development (Capute et al. 1985). In the present study, there is significant association between IQ and hyperactivity as it regarded to be more prevalent among the higher IQ children, on the other side a previous study revealed that there is a weak association between IQ and hyperactivity (Jespsen et al 2008) which needs further study.

In the present study, there is significant difference between the two groups (lower and higher IQ); the total leukocytic count was higher value for low IQ children group, which goes with a study by Strouse et al. (2006) which revealed that elevated white blood cells are associated with lower IQ.

In the present study, there is no significant difference in the $\mathrm{Hb}$ level between the two groups of lower and higher IQ, on the other hand a previous study showed that low hemoglobin level has negative effect on the children cognition (Ai et al. 2012) that needs further study.

In the present study showed no significant difference in platelets count and volume between two groups of children (of higher and lower IQ); in a previous study revealed that there is no significant difference in platelets count and volume between normal and autistic and schizophrenic children (Geller et al. 1988).

In the present study, the water intake is inversely proportional to IQ level; a study revealed that the 
concentration of fluoride in drinking water has direct effect on the IQ of children (Razdan et al. 2017).

In the present study, the caloric intake is inversely proportional to IQ level; in the previous study, malnutrition has direct effect on child development (Ampaabeng and Tan 2013).

In the present study, the carbohydrate intake is inversely proportional to IQ level and this correlation close to be significant. Previous study applied on Tehrani children aged 6-7 years gave evidence, indicating an inverse relationship between refined carbohydrate consumption and non-verbal intelligence (Abargouei et al. 2012).

In the present study, there is a significant correlation between protein intake and IQ level of children, as the protein intake is inversely proportional to IQ. In the previous study revealed that increased protein intake in the first weeks of life increases the mental development of newborn (Stephens et al. 2009).

In the present study, the fat intake is inversely proportional to IQ level with significant difference between the two groups of lower and higher IQ, which goes with a study by Theodore et al. (2009) that applied on European children of age 5-7 years old revealed that eating margarine at least daily was associated with significantly lower IQ scores.

In the present study, there is significant correlation between fiber intake and IQ level, on the other hand the fiber intake is inversely proportional to IQ level of children which goes against recent nutritional researches have found that dietary fiber was directly related with cognitive development among prepubertal children. Fiber intake may have a significant effect on cognitive and brain health through immunomodulation and/or the gut-microbiota-brain system (Khan et al. 2015) which needs further study.

In the present study, there was significant correlation between sodium intakes with IQ, the sodium intake is inversely proportional to IQ level of children. In the previous study showed no relation between sodium intake and IQ level of children (Ghazi et al. 2013).

In the present study, there is significant correlation between IQ and potassium intake, in which it is inversely proportional to IQ level of children, this results against a study by Ghazi et al. (2013) revealed that no relationship between IQ and potassium intake, which needs further study.

In the present study, calcium and iron showed no significant correlation with IQ of children which goes with the previous study by Ghazi et al. (2013) in the present study zinc and vitaminB2 intake showed significant correlation with IQ of children which goes against a study by Ghazi et al. (2013) that showed no correlation between zinc and vitamin B2intake and children IQ level, that needs further study.

\section{Conclusion}

Intellectual disability is more prevalent in rural and popular residential. As the birth order increases, the percentage of lower IQ increases. The gross motor development is directly proportional to IQ. The total leukocytic count was higher value for low IQ children group. Dietary profile for intellectually disabled children (of lower IQ) is regarded to be richer with dietary elements and vitamins than that for higher IQ children. According to the multiple analysis, orientation is the most related variable and zinc intake is the most effective variable on the IQ scores.

\section{Recommendations}

Screening for IQ among children in rural and popular area, assessment for intellectually disabled and developmentally delayed children, regular follow-up for these children is a must. In case of higher birth order child (more than the second), IQ assessment must be carried out. Increasing the nutritional awareness between parents increases zinc intake for children from natural sources such as meat which is an excellent source of zinc, shellfish which regarded to be healthy, low-calorie sources of zinc, legumes like chickpeas, lentils, and beans that all contain substantial amounts of zinc, also seeds, nuts, dairy, eggs, and whole grains.

\section{Abbreviations \\ IQ: Intelligence quotient; Hb: Hemoglobin; BMI: Body mass index; WHO: World Health Organization; MPR: Multiple Pass Food Recall; USDA: United State \\ Department of Agriculture; CNS: Central nervous system; CVS: Cardiovascular system; EEG: Electroencephalogram; TLC: Total leukocytic count.}

\section{Acknowledgements}

First and foremost, I feel always indebted to Allah, the most kind and most Merciful. I would like to express my deep appreciation and thanks to all the staff of the general pediatric clinic referred to Center of children with special needs, Faculty of Post Graduate Childhood Studies, Ain Shams University for their help. My sincere thanks and appreciation to all parents of patients participated in this study for their cooperation. Deep thanks to the IT-Department in the National Institute of Nutrition for their accurate performance in food analysis of cases. I would like to express my appreciation and deep thanks to Dr. Ahmed Abdel Gawad lecturer in the institution of the environmental studies for his help.

\section{Authors' contributions}

This study was applied on children attending the clinic of center of special needs children, the head of Faculty of Post Graduate Childhood Studies; HE gave a consent for recruit cases from the clinic that referred to the Faculty of Post Graduate Childhood Studies. RM carried out the clinical examination of children and diagnosis of cases also helps to put a classification for the recruited cases. MM carried out the statistical analysis and helps to find the correlations between variables. MK helps in selection of the nutritional questioners used in the study and assists in food analysis. MA, the corresponding author, attends the clinic of center of special needs children, and recruits the cases, collects the medical reports and data, also helps the caregivers to fill out the nutritional questioners and collects it, and sends it to the National 
Institute of Nutrition, makes correlation between medical and nutritional data. All authors have read and approved the manuscript.

\section{Funding}

This research did not receive any specific grant from funding agencies in the public, commercial, or not-for-profit sectors, and funded by the corresponding author.

\section{Availability of data and materials}

The datasets generated during and/or analyzed during the current study are not publicly available due [General agreement among the authors] but are available from the corresponding author on reasonable request.

\section{Ethics approval and consent to participate}

Ethics committee full name: Ethical committee (referred to the Faculty of Post Graduate Childhood Studies-Ain Shams University approval was obtained before starting the study. Caregivers of the children involved in the study were informed by plain simple explanation of the study, and verbal informed consent was obtained also a written informed consent can be obtained from caregivers. Confidentiality of patient's healthcare data was always be ensured.

\section{Consent for publication}

Not applicable.

\section{Competing interests}

This study will serve for increasing information about nutritional status and its correlation with intellectual disability in children, which contribute to the enhancement of healthcare process. Moreover, this goes with the research plan of the department toward developing good healthy environment.

\section{Author details}

1 Institute of Environmental Studies and Research, Ain Shams University, El-Abaseya, Egypt. ${ }^{2}$ Faculty of Post Graduate Childhood, Ain Shams University, El-Abaseya, Egypt. ${ }^{3}$ Faculty of Post Graduate Childhood Studies, Ain Shams University, El-Abaseya, Egypt. ${ }^{4}$ The National Institute of Nutrition, Tarnaka, India.

Received: 26 July 2020 Accepted: 25 October 2020

Published online: 07 November 2020

\section{References}

Abargouei A, Janghorbani M, Salehi-Marzijarani M, Esmaillzadeh A (2012) Effect of dairy consumption on weight and body composition in adults: a systematic review and meta-analysis of randomized controlled clinical trials. Int J Obes 36:1485-1493

Ai Y, Zhao S, Zhou G, Ma X, Liu J (2012) Hemoglobin status associated with performance IQ but not verbal IQ in Chinese preschool children. Pediatr Int J 54(5):669-675

Capute A, Shapiro B, Palmer F, Ross A, Wachtel R (1985) Cognitive-motor interactions: the relationship of infant gross motor attainment to $I Q$ at 3 years. SAGE J 24(12):671-675

Chang SY, Wang L, Wang YY (2011) Iron-deficiency anemia in infancy and social emotional development in preschool-aged Chinese children. Pediatrics 127:E927-E933

Geller E, Yuwiler A, Freeman B, Ritvo E (1988) Platelet size, number, and serotonin content in blood of autistic, childhood schizophrenic, and normal children. J Autism Dev Disorders 18:119-126

Ghazi H, Isa Z, Aljunid S, Shah S, Abdalqader M (2013) Intelligence Quotient (IQ) relationship with energy intake and micronutrient composition among primary school children in Baghdad City. Iraq Pakistan J Nutrit 12(2):200-204

Hardya S, Kleinman R (2007) Fat and cholesterol in the diet of infants and young children: Implications for growth, development, and long-term health. J Pediatr 125(5):S69-S77

Houwen S, Visser L, der Putten A, Vlaskamp C (2016) The interrelationships between motor, cognitive, and language development in children with and without intellectual and developmental disabilities. Res Dev Disabil 53-54:19-31

Jespsen J, Fagerlund B, Mortensen E (2008) Do attention deficit influence IQ assessment in children and adolescents with ADHD? J Attent Disorder 12(6):551-562

Khan N, Raine L, Drollette E, Scudder M, Kramer A, Hillman C (2015) Dietary fiber is positively associated with cognitive control among prepubertal children. J Nutrit 145(1):143-149

Krebs-Smith S, Guenther P, Subar A, Kirkpatrick S, Dodd K (2010) Americans do not meet federal dietary recommendations. J Nutr 140:1832-1838

Kristensen P, Bjerkedal T (2007) Explaining the relation between birth order and intelligence. Science 316(5832):1717

Lakhan R, Ekúndayò T, Shahbazi M (2015) An estimation of the prevalence of intellectual disabilities and its association with age in rural and urban populations in India. J Neurosci Rural Pract 6(4):523-528

Lai M-C, Lombardo MV, Pasco G, Ruigrok ANV, Wheelwright SJ, Sadek SA, Chakrabarti B, Consortium MRC, Cohen SB (2011) A behavioral comparison of male and female adults with high functioning autism spectrum conditions. Plos One J. 6:e20835

Lin J, Lin P, Lin L, Hsu S, Loh C, Yen C, Fang W, Chien W, Tang C, Wu C (2010) Prevalence and associated risk factors of anemia in children and adolescents with intellectual disabilities. ELSEVIER J 31(1):25-32

Lozoff B, Beard J, Connor J, Felt B, Georgieff M, Schallert T (2006) Long-lasting neural and behavioral effects of iron deficiency in infancy. Nutr Rev 64:S34-543

Luna B (2009) Developmental changes in cognitive control through adolescence. Adv Child Dev Behav 37:233-278

Mason J, Bailes A, Beda-Andourou M (2005) Recent trends in malnutrition in developing regions: vitamin A deficiency, anemia, iodine deficiency, and child underweight. Food Nutr Bull 26:59-108

Moshfegh A, Baer D, Rhodes D, Murayi T (2008) The US Department of Agriculture Automated Multiple-Pass Method reduces bias in the collection of energy intakes. Am J Clin Nutr 88(2):324-332

Mostafa M, El shorbagy O, (2010) Medical information research services design. Elsevier, New York

Razdan P, Patthi B, Kumar I, Agnihotri N, Chaudhari P, Prasad M (2017) Effect of fluoride concentration in drinking water on intelligence quotient of 12-14-year-old children in Mathura district: a cross-sectional study. J Int Soc Prev Community Dent 7(5):252-258

Rintala P, Loovis M (2013) Measuring motor skills in Finnish children with intellectual disabilities. SAGE J 116(1):294-303

Stephens B, Walden R, Gargus R, Tucker R, McKinley L, Mance M, Nye J, Vohr B (2009) First-week protein and energy intakes are associated with 18-month developmental outcomes in extremely low birth weight infants. Pediatrics 123(5):1337-1343

Strouse J, Cox C, Melhem E, Lu H, Kraut M, Razumovsky A, Yohay K, van Zijl P, Casella J (2006) 2006): Inverse correlation between cerebral blood flow measured by continuous arterial spin-labeling (CASL) MRI and neurocognitive function in children with sickle cell anemia (SCA. Blood 108(1):379-381

Tambi M, Ewane E (2019) Implications of family size on students educational attainment in Cameroon. Int J Econ Manag 1(4):25-36

Taylor DJ, Davidson J, Howie PW, Davidson D, Drillien CM (1985) Do pregnancy complications contribute to neurodevelopmental disability? Lancet J

Theodore R, Thompson J, Waldie K, Wall C, Becroft D, Robinson E, Wild C, Clark P, Mitchell E (2009) Dietary patterns and intelligence in early and middle childhood. Intelligence 37(5):506

WHO Child Growth Standards: length /height-for-age, weight-for-age, weightfor-length, weight-for height and body mass index-for-age. Methods and development. Geneva, Switzerland: World Health Organization, 2005-2007.

\section{Publisher's Note}

Springer Nature remains neutral with regard to jurisdictional claims in published maps and institutional affiliations. 